\title{
HVAC CFD Analysis of Air Flow and Temperature Distribution Inside Passenger Compartment
}

\author{
Muhamad Haziq Mohammad Aris ${ }^{1}$, Nofrizalidris Darlis ${ }^{1^{*}}$, Izuan Amin Ishak ${ }^{\mathbf{1}}$, \\ Syabillah Sulaiman ${ }^{1}$, Norrizam Jaat ${ }^{1}$, Abdul Fathul Hakim ${ }^{1}$
}

${ }^{1}$ Centre of Automotive and Powertrain Technology, Faculty of Engineering Technology,

Universiti Tun Hussein Onn Malaysia, 84600 Pagoh, Johor, MALAYSIA

*Corresponding Author

DOI: https://doi.org/10.30880/japtt.2021.01.01.003

Received 24 August 2021; Accepted 11 October 2021; Available online 16 Disember 2021

\begin{abstract}
The thermal environment and air quality in a passenger car can affect driver's and passengers' health, performance and comfort. Due to spatial and temporal variation of state variables and boundary conditions in the vehicle cabin, the heating, ventilating and air-conditioning (HVAC) does not have to be designed to provide a uniform environment. This are due to individual differences regarding to physiological and psychological response, clothing insulation, activity, air temperature and air movement preference. Experimental study in vehicle HVAC system can be very costly to be conducted. In order to analyze the air flow and temperature distribution in passengers compartment, a numerical simulation was used in this study to analyze the air flow and temperature distribution of HVAC unit inside Proton Exora passengers compartment, with the air blower speed and air temperature used as parameter, to evaluate the airflow behavior and temperature distribution in the compartment. The simulation data obtained is then compared to the experimental data, showing good agreement between these two methods.
\end{abstract}

Keywords: CFD analysis, HVAC, passengers' compartment, air flow behaviour, temperature distributions

\section{Introduction}

The enhancement of technology in automotive industry has led this sector to improve every aspect of the vehicle performance, design, comfort, and safety. The environment inside the passenger compartment has also considered to improve the comfort of the passenger. This is a crucial factor as people has spent more time in vehicle for mobility. A good distribution of air temperature is important for providing a fresh and healthy air for passengers in the cabin as poor ventilation can affect the passenger's health [1-4]. Thus, it is necessary to improve the ventilation of air flow in vehicles by its design process. Recently, the implementation of the computational dynamics (CFD) technique used in this vehicle design development has greatly reduced the time and cost.

The purpose of this study was to evaluate the air flow and temperature distribution inside the passenger's compartment. The outside environment temperature was set to room temperature. the parameter of the air inlet vent is taken according to the measured experimental value. The numerical simulation was conducted by using ANSYS 19.1.

\section{Literature Review}

Several vehicle model has been studied during the past in order to investigate the airflow behavior and temperature distribution of the vehicle's HVAC system. The studies are performed to understand the relation of vehicle's design to the environment of the passenger car compartment. Haslinda M. has performed a study of air-flow and temperature field in a passenger car compartment on Proton Wira which is a sedan. The 3D model developed in this study included 
human models based on a male person with body weight of $65 \mathrm{~kg}$ and medium heght, set at 90 degrees posture. The air flow condition and temperature distribution in the model was shown [1]. Paul Danca studied cabin thermal environment by CFD simulation of Renault Megane. He states that the complex geometry of the interior cabin and the complexity of the HVAC system itself are the obstacle for the researchers to understand the flow pattern formed [2]. Huajun Z. studied the air flow and temperature fields inside passenger compartment of Volkswagen Passat sedan. The result of the numerical simulation model in this study are validated with the experimental result with the same parameter, that are carried out in the environment test room. The measured and the predicted results in the study shows a good agreement when compared [3].

Taeyoung H.list out seven steps in Virtual Thermal Comfort Engineering (VTCE) analysis for "soak and cooldown simulation in the study. The parameter that needs to be considered for this scope of study was also shown [4]. Jin Woon L. did a study focusing of spectral solar radiation, without adding virtual manikin in the simulation. The results obtained by observing the air flow and thermal distribution of the numerical model in this study are discussed to analyze the effect of solar radiation [5]. C.-H. Chien performed a study by using STAR-CD software to evaluate thermal comfort of car passenger compartment using extended k-e as its turbulence model, Predicted Mean Value (PMV) is used to show the rating of the thermal comfort of the passenger [6]. Jalal M. et al. analyse CFD simulation by treating the flow as steady state to show the capability of CFD to predict the air flow in mobile cabin accurately [7]. Kilic M. did a study of a vehicle cabin CFD model with virtual manikin with real dimensions and physiological shape, adding heat transfer between human body surface and cabin environment [8]-[10].

John P. Rugh did a study on reduction in vehicle temperature and fuel use from cabin ventilation, solar reflective paint, and solar reflective glazing. Fluent and RadTherm software is used for thermal analysis, validated by quasi steady-state soak data of the experimental test [11]. A. Fujita et al. did a study to predict thermal environment inside a vehicle cabin. He claims that the cooling air tends to reach the rear seats more easily with the introduction of outside air than with internal air circulation [12-14]. Joo H. M. et al. apply solar radiation effect in their parameter to analyse thermal comfort in passenger compartment by using ANSYS Fluent software with standard k-e as its turbulence model [15-20].

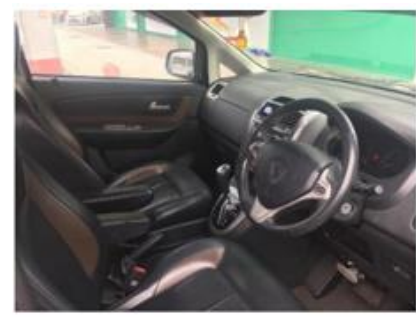

inlet vents: $30 \mathrm{~mm} \times 150 \mathrm{~mm}$

inlet vents: $85 \mathrm{~mm} \times 55 \mathrm{~mm}$
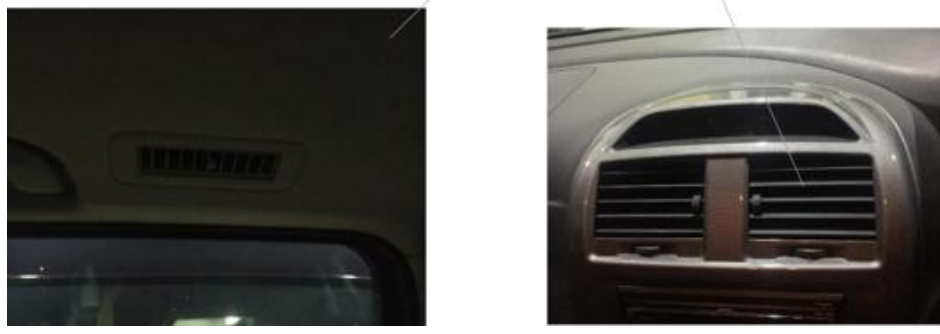

Fig. 1 - Physical model of Proton Exora Bold

\section{Experimental Setup}

For experimental setup, the vehicle was parked at covered parking area where the ambient temperature is at $23^{\circ} \mathrm{C}$. the HVAC unit of the vehicle was turned on for 1 hour to achieve steady state condition inside the cabin. all the inlet air vents were set to direct its flow direction normal to its surface. the HVAC temperature control knob is set to a fixed position through the experiment. All four level of blower fan speed air velocity and temperature are recorded for boundary conditions in numerical simulation.

The inlet air vent velocity and temperature in this experiment was recorded by using digital anemometer that measures wind speed, wind volume and wind temperature. the measurement points are given in Figure 1. The measurement points temperature is measured by using bimetallic thermometer. 


\begin{tabular}{|l|l|}
\hline Points & Locations \\
\hline P1 & Head level (front passenger) \\
\hline P2 & Chest level (front passenger) \\
\hline P3 & Knee level (front passenger) \\
\hline P4 & Feet level (front passenger) \\
\hline P5 & Head level (driver) \\
\hline P6 & Chest level (driver) \\
\hline P7 & Knee level (driver) \\
\hline P8 & Feet level (driver) \\
\hline
\end{tabular}

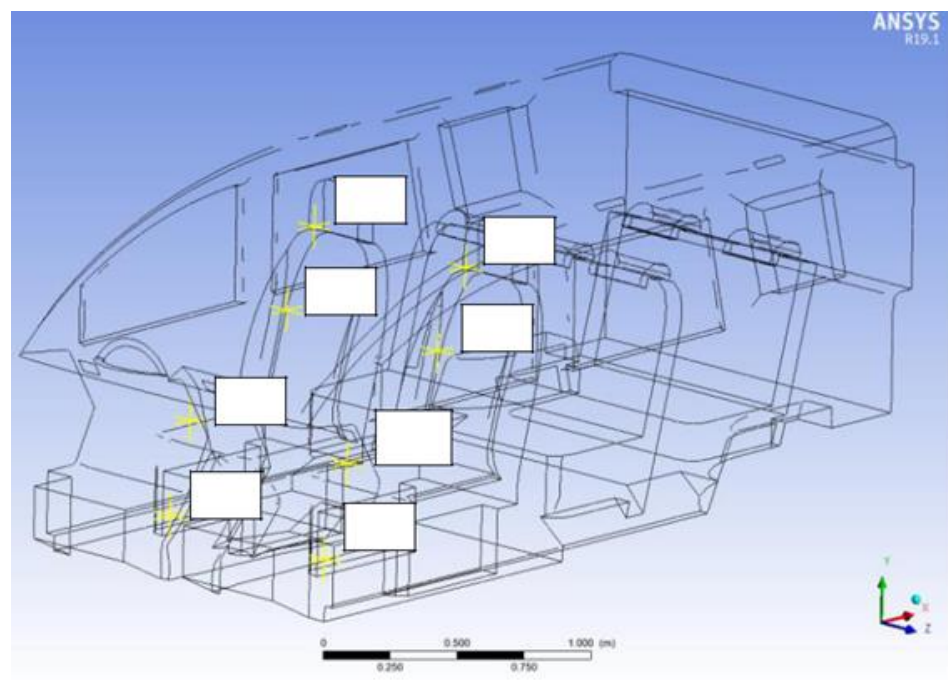

Fig. 2 - Location of measurement temperature points for experiment and numerical analysis.

\subsection{Numerical Simulation}

Figure 1 presents the physical model used in this study, a seven-seater MPV model with eight inlet AC vent, and 2 outlet vents. The inlet vents are separated with two different blower fan, four inlets with cross sectional area of $85 \mathrm{~mm}$ x $55 \mathrm{~mm}$, located at the slope of the dashboard of the model which are using primary blower fan. The remaining four inlet vent are located at the roof of the compartment with cross sectional area of $30 \mathrm{~mm} \times 150 \mathrm{~mm}$, using secondary blower fan. Two outlet vents are located at near to the rear passenger's seat, with surface area of $0.01448 \mathrm{~m}^{2}$.

In this study, ANSYS Fluent was used to solve the numerical simulation to investigate airflow and temperature distribution. This software was chosen for this study because most of previous studies that has been done are using this software that gives good agreement between predicted and actual results. Steady state analysis was used in this study to reduce the results that needed to be analyze. Only few researchers have used steady state type of flow to reduce the data analysis and calculation at results and discussion. Standard k-e turbulent model is used in this study. This turbulence model is generally used for such calculations due to stability and precision of numerical results. previous study also claimed this turbulent model are more appropriate for indoor flow modelling. The wall conditions are treated as rigid stationary wall and no slip shear condition.

\subsection{Modelling Geometry}

The 3D model for this study was developed by using SolidWorks 2017 software. The model in this study has simplified geometry design compared to the physical model, as the geometry are complex. The 3D model is shown in figure 3 .

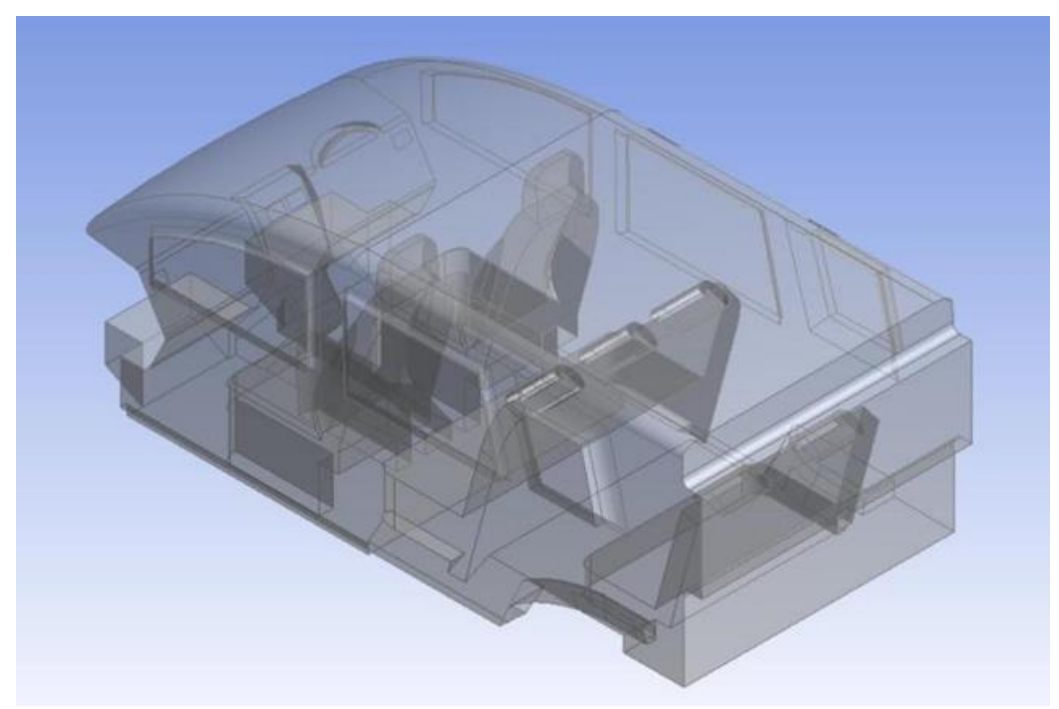

Fig. 3 - Simplified 3D model of Proton Exora Bold 


\subsection{Meshing Structure}

In numerical calculations, mesh structure of the computational domain is very important for getting predicted results in good accuracy and reducing computing time. The volume of the dashboard, seats, and instrument panel were excluded from the meshing process since they were treated as solid bodies. Car model was meshed by using ANSYS software. In this study, 3-D tetrahedral mesh was used in the present computations. This mesh structure contains triangular elements on the surfaces, tetrahedral elements in the volume region. The surface mesh had a maximum skewness of 0.9 and max size of $0.40309 \mathrm{~m}$.

\begin{tabular}{|c|c|}
\hline Object Name & Mesh \\
\hline State & Solved \\
\hline \multicolumn{2}{|l|}{ Display } \\
\hline Display Style & Body Color \\
\hline \multicolumn{2}{|l|}{ Defaults } \\
\hline Physics Preference & CFD \\
\hline Solver Preference & Fluent \\
\hline Element Order & Linear \\
\hline Element Size & Default $(0.20155 \mathrm{~m})$ \\
\hline Export Format & Standard \\
\hline Export Preview Surface Mesh & No \\
\hline \multicolumn{2}{|l|}{ Sizing } \\
\hline Use Adaptive Sizing & No \\
\hline Growth Rate & Default (1.2) \\
\hline Max Size & Default $(0.40309 \mathrm{~m})$ \\
\hline Mesh Defeaturing & Yes \\
\hline Defeature Size & Default $(1.0077 \mathrm{e}-003 \mathrm{~m})$ \\
\hline Capture Curvature & Yes \\
\hline Curvature Min Size & Default $(2.0155 \mathrm{e}-003 \mathrm{~m})$ \\
\hline Curvature Normal Angle & Default $\left(18.0^{\circ}\right)$ \\
\hline Capture Proximity & No \\
\hline Bounding Box Diagonal & $4.0309 \mathrm{~m}$ \\
\hline Average Surface Area & $9.1751 \mathrm{e}-002 \mathrm{~m}^{2}$ \\
\hline Minimum Edge Length & $8.651 \mathrm{e}-006 \mathrm{~m}$ \\
\hline \multicolumn{2}{|l|}{ Quality } \\
\hline Check Mesh Quality & Yes, Errors \\
\hline Target Skewness & Default $(0.900000)$ \\
\hline Smoothing & Medium \\
\hline Mesh Metric & None \\
\hline
\end{tabular}

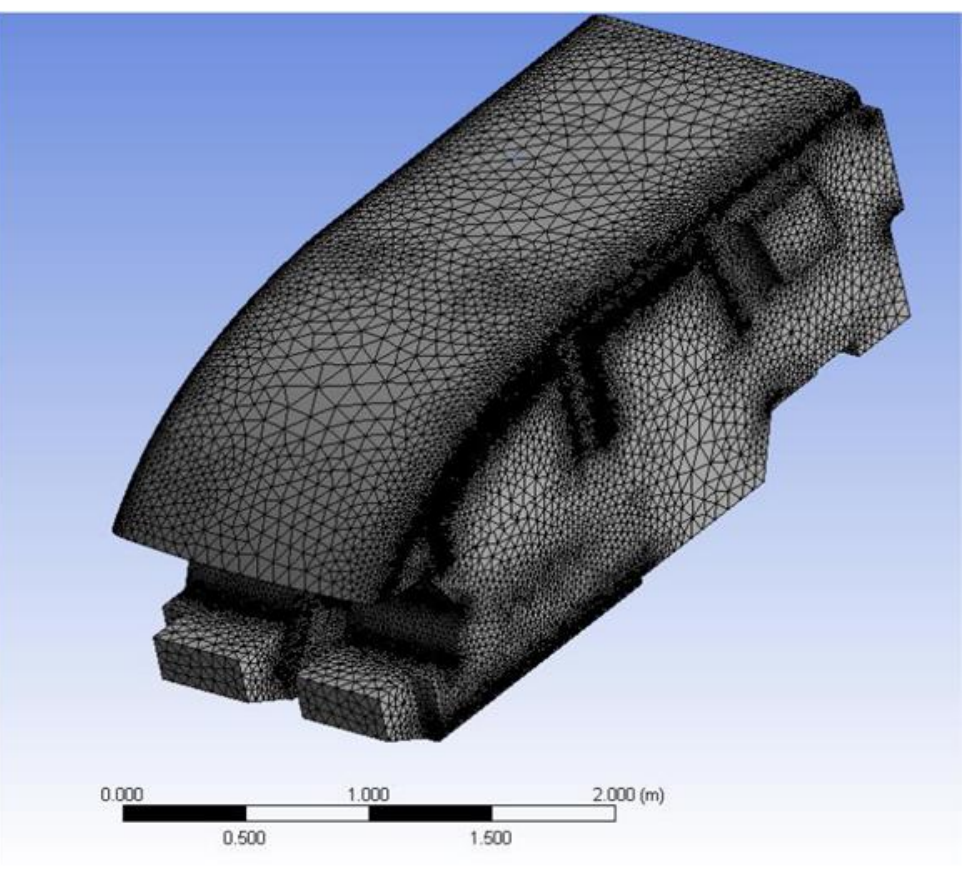

Fig. 4 - Information of solid mesh

\subsection{Boundary Conditions}

The CFD analysis of air flow and temperature distribution inside passenger compartment was performed in this study with a specific boundary condition. The boundary condition in this study were based on the collected data measured in experimental setup for this study. the parameter that are used in this simulation involves air velocity, air temperature, heat gain through passenger's compartment. The heat gain through passenger's compartment was set to room temperature at $23^{\circ} \mathrm{C}$.

\subsection{Results and Discussion}

The results of air flow behavior and temperature distribution inside passenger's compartment are presents. The temperature value of specified points was compared between measured and predicted values to find the accuracy of the simulation. Then, the air flow behavior and temperature distribution within the compartment were investigated and discussed. The evaluation of the human comfort of the passenger were performed based on the results obtained.

To run this simulation, a three-dimensional steady state model of selected vehicle passenger's compartment was developed. This simulation was done on several inlet air velocity with its respective temperature based on table 1 . The parameter was kept constant are the wall temperature, Twall $=23^{\circ} \mathrm{C}$. 
Table 1 - Parameter of Boundary Condition in Numerical Simulation

\begin{tabular}{|c|c|c|c|c|}
\hline \multirow{2}{*}{$\begin{array}{c}\text { Blower } \\
\text { Fan } \\
\text { Speed }\end{array}$} & \multirow{2}{*}{$\frac{\text { Inlet air }}{(\mathrm{m} / \mathrm{s})}$} & \multirow{2}{*}{$\begin{array}{c}\text { Flow } \\
\text { rate }\end{array}$} & \multicolumn{2}{|c|}{ Temperature $\left({ }^{\circ} \mathrm{C}\right)$} \\
\hline & & & & \\
\hline & Front & Roof & Front & Roof \\
\hline 1 & 2.51 & 2.06 & 14.6 & 17.6 \\
\hline 2 & 3.79 & 2.83 & 12.9 & 17.3 \\
\hline 3 & 5.63 & 3.64 & 12.1 & 16.8 \\
\hline 4 & 7.93 & 5.63 & 11.6 & 16.6 \\
\hline
\end{tabular}

\subsection{Validation of the Predicted Results by Comparison}

The validation of the predicted value was performed in this study to find the accuracy of the results. Temperature predicted and measured value are taken at various point at the compartment. Location of the measurement points are shown in figure 2. Table 2 and Table 3 shows the predicted and measured value at specified locations. The accuracy of the simulation model was calculated by finding the percentage of accuracy between the predicted and measured value. Figure 5 shows the graph of measured and predicted value.

Table 2 - Measured temperature value at specified locations

\begin{tabular}{|c|c|c|c|c|c|}
\hline \multirow[t]{2}{*}{ Points } & \multirow[t]{2}{*}{ Locations } & \multicolumn{4}{|c|}{ Measured temperature value $\left({ }^{\circ} \mathrm{C}\right)$} \\
\hline & & Blower 1 & Blower 2 & Blower 3 & Blower 4 \\
\hline $\mathrm{P} 1$ & Head level (front passenger) & 16.9 & 16.0 & 15.6 & 15.6 \\
\hline $\mathrm{P} 2$ & Chest level (front passenger) & 17.2 & 16.3 & 15.6 & 15.3 \\
\hline P3 & Knee level (front passenger) & 17.1 & 16.4 & 16.0 & 15.5 \\
\hline $\mathrm{P} 4$ & Feet level (front passenger) & 17.9 & 17.1 & 16.3 & 16.1 \\
\hline P5 & Head level (driver) & 17.0 & 16.1 & 15.5 & 15.3 \\
\hline P6 & Chest level (driver) & 17.2 & 16.3 & 15.6 & 15.2 \\
\hline P7 & Knee level (driver) & 17.2 & 16.5 & 15.9 & 15.6 \\
\hline P8 & Feet level (driver) & 17.7 & 16.9 & 16.1 & 15.4 \\
\hline
\end{tabular}

Table 3 - Predicted temperature value at specified locations

\begin{tabular}{|l|l|l|l|l|l|}
\hline Points & Locations & \multicolumn{3}{l}{ Predicted temperature value $\left({ }^{\circ} \mathrm{C}\right)$} & \\
\cline { 3 - 6 } & & Blower 1 & Blower 2 & Blower 3 & Blower 4 \\
\hline P1 & Head level (front passenger) & 17.1 & 16.3 & 16.0 & 15.9 \\
\hline P2 & Chest level (front passenger) & 17.5 & 16.7 & 15.9 & 15.7 \\
\hline P3 & Knee level (front passenger) & 17.4 & 16.8 & 16.2 & 15.3 \\
\hline P4 & Feet level (front passenger) & 18.2 & 17.4 & 16.5 & 16.6 \\
\hline P5 & Head level (driver) & 17.2 & 16.2 & 15.9 & 15.8 \\
\hline P6 & Chest level (driver) & 17.5 & 16.7 & 15.9 & 15.5 \\
\hline P7 & Knee level (driver) & 17.9 & 16.8 & 16.1 & 15.4 \\
\hline P8 & Feet level (driver) & 18.1 & 17.2 & 16.7 & 16.3 \\
\hline
\end{tabular}




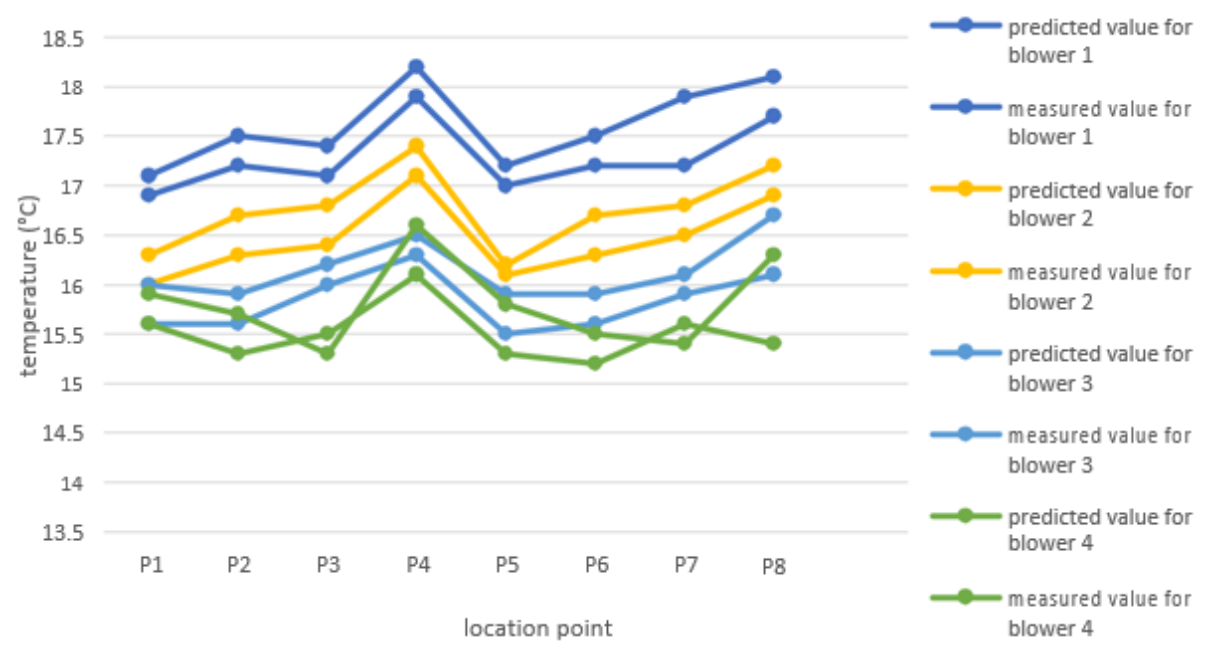

Fig. 5 - Graph comparison of predicted and measured values.

Table 4 - Accuracy percentage of error

\begin{tabular}{|l|r|r|r|r|}
\hline \multirow{2}{*}{$\begin{array}{l}\text { Location } \\
\text { point }\end{array}$} & \multicolumn{5}{|l|}{ Percentage of error $(\%)$} & Blower 4 \\
\cline { 2 - 6 } & Blower 1 & Blower 2 & Blower 3 & 4.2 \\
\hline P1 & 4.5 & 4.1 & 3.6 & 3.7 \\
\hline P2 & 3.8 & 3.5 & 4.2 & 7.3 \\
\hline P3 & 3.9 & 3.4 & 4.7 & 2.9 \\
\hline P4 & 3.7 & 3.9 & 4.6 & 3.1 \\
\hline P5 & 4.4 & 5.3 & 3.6 & 4.3 \\
\hline P6 & 3.8 & 3.5 & 4.2 & 7.2 \\
\hline P7 & 1.7 & 4.0 & 4.7 & 0.6 \\
\hline P8 & 3.2 & 3.9 & 2.3 & \\
\hline
\end{tabular}

Table 4 shows the calculated percentage of accuracy between the predicted and measured value at specified points. The maximum percentage of error obtained are $7.3 \%$ by blower 4 located at front passenger's knee level. The minimum percentage of error obtained are $0.6 \%$ by blower 4 located at driver's feet level. The percentage of accuracy calculated shows good agreement between both values. This is important in order to further the investigation of the numerical simulation, as the accuracy of the predicted results is known.

\subsection{Air Flow Behavior Inside Passenger's Compartment}

Table 5 and shows the results of air flow velocity vector by different air inlet velocity located at XY plane at the middle of the compartment. The red area in the contour represents the maximum air velocity while the blue area represents low air velocity vector. Table 6 shows the air streamline and volume rendering of air velocity by blower 4 within the passenger's compartment to get 3D overview of air flow behaviour. 
Table 5 - Air velocity vector by different inlet blower fan speed

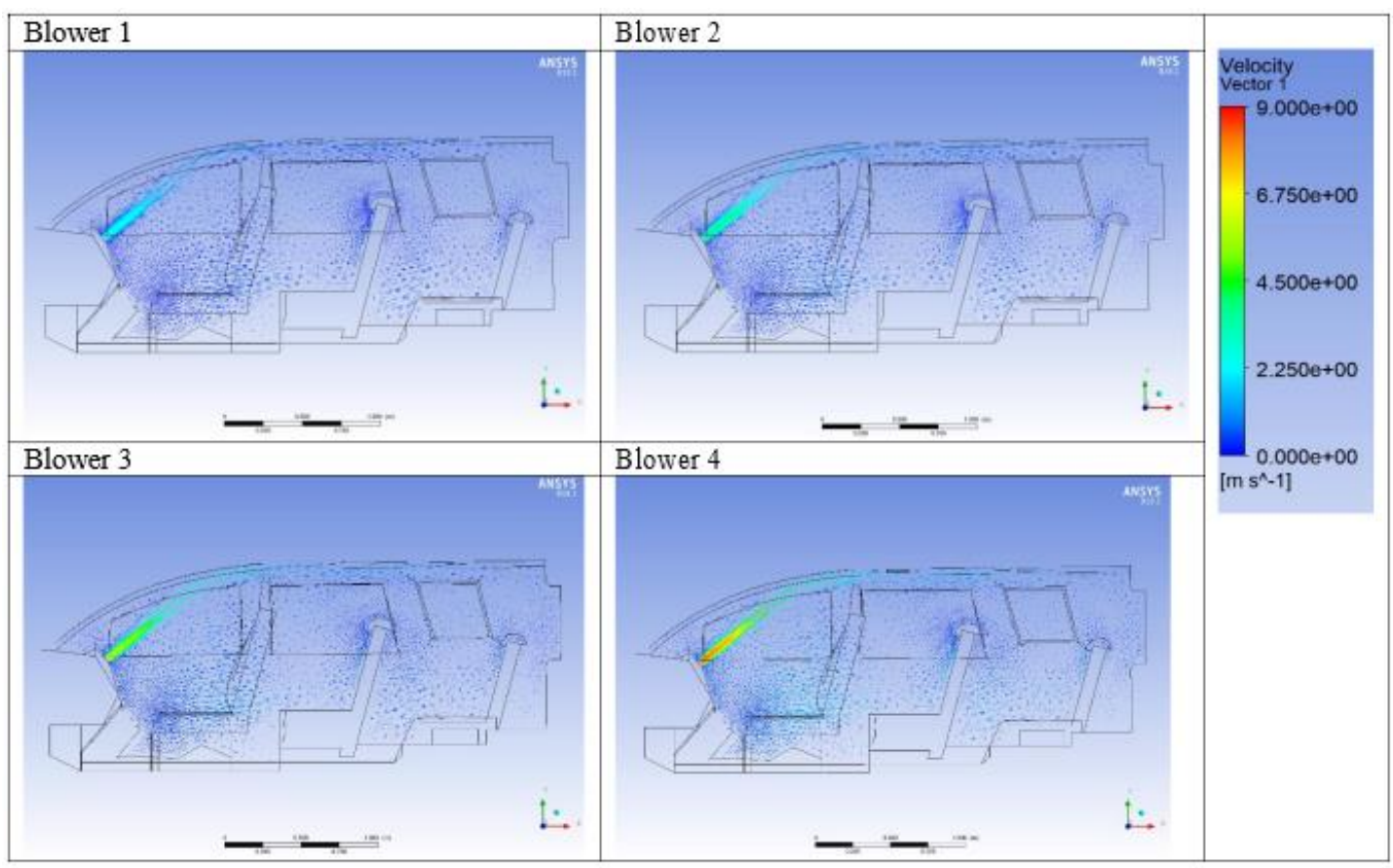

Table 6 - 3D volume rendering and air stream line of simulation

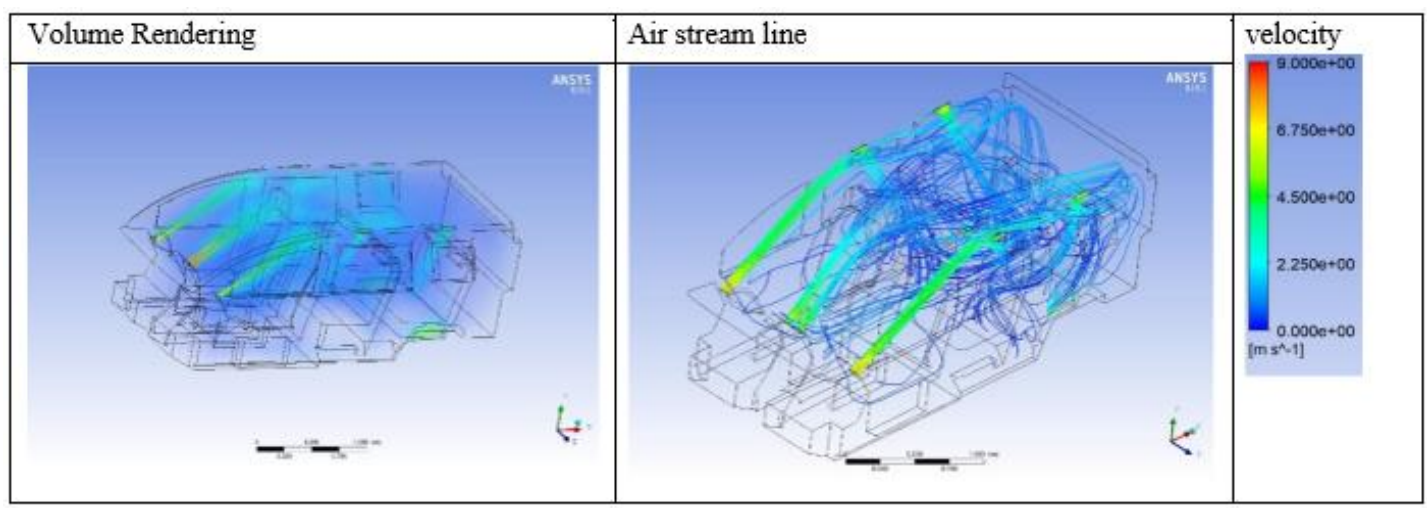

From the observation, the magnitude of velocity flow of the inlet air from four different blower fan air speed shows similar air flow behaviour in the passenger's compartment in steady state conditions. in general, the air flows are almost symmetrically distributed in the cabin. The air stream from the front air inlet vents were delivered to the rear compartment and the air stream from inlet vent located at the roof of the cabin disrupts the air delivered to redirects the air stream to the middle and rear compartment. Some of the air stream from the middle compartment flowed back to front compartment through the gap between front seats and produce large recirculation vortices between the dashboard and the front seats. Uniform air velocity distribution occurred at the rear of the compartment.

The concentration of velocity vectors can be seen at the rear seat of the compartment due to the outlet flow through the outlet vent. The difference that can be observe by comparing blower fan speed to air flow distribution is higher inlet air velocity can distribute cool air with much more effective by producing more turbulence and faster recirculation vortices within the passenger's compartment.

\subsection{Temperature Distribution Inside Passenger's Compartment}

Table 6 shows the contour of temperature distribution by different air inlet velocity located at XY plane at the middle of the compartment. The red area in the contour represents the high air temperature while the blue area represents low air temperature. 
Table 6 - Temperature distribution contour by different inlet blower fan speed

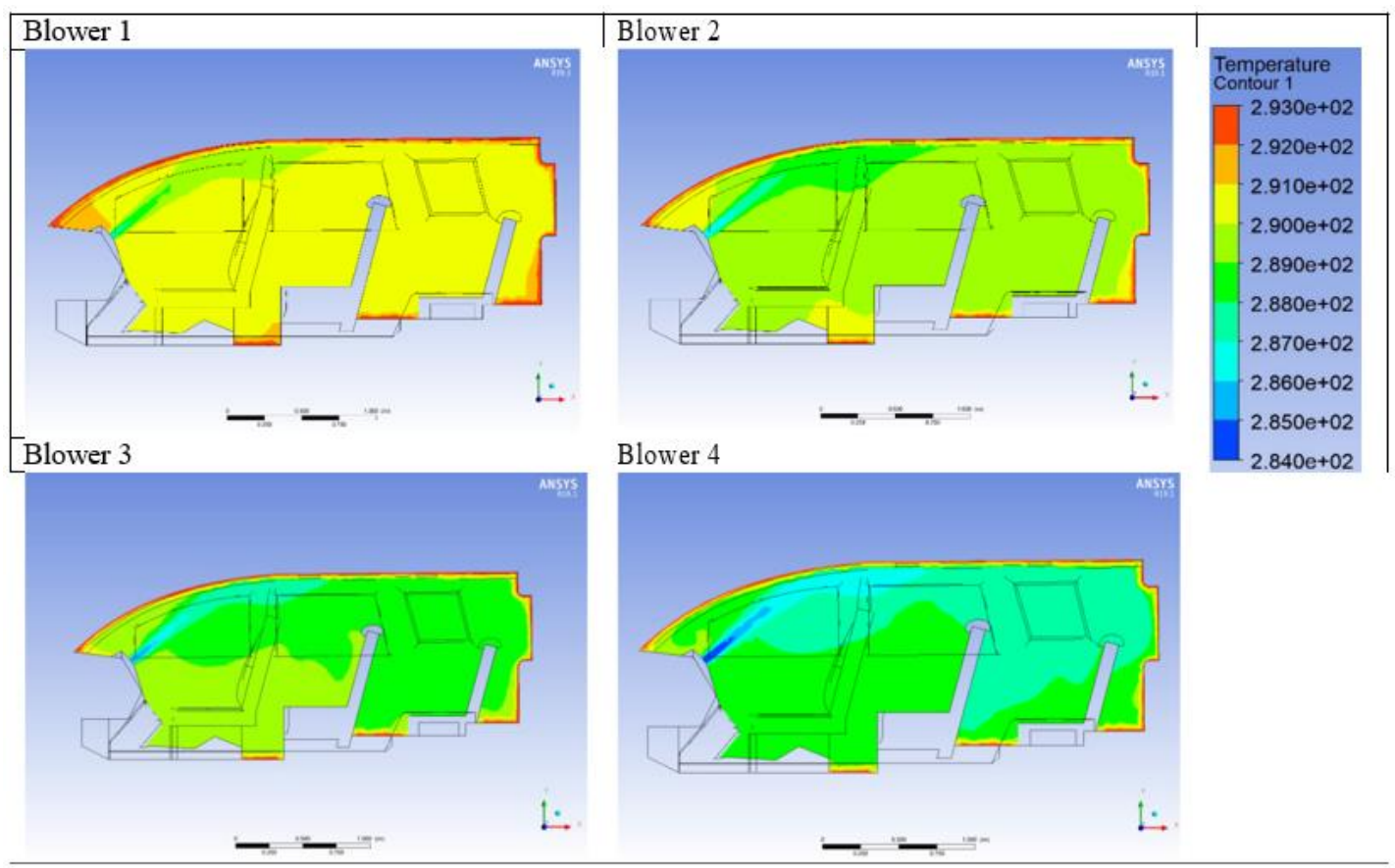

Based on Table 2, the temperature distribution of the passenger's compartment from four different blower fan air speed shows difference of temperature contour in steady state conditions. High surface temperatures were predicted at the roof and floor of the compartment due to outside ambient temperature. As the air stream recirculates at the front compartment, the temperature contour tends to follow the rotating vortices within the compartment. The decrease of high temperature contour near the passenger's feet at front compartment as higher inlet air velocity were due to the air stream were obstructed by front seat to the area.

\subsection{Conclusion}

The purpose of this study was to create a numerical model to evaluate the air flow behaviour and temperature distribution in Proton Exora passenger's compartment, and to compare the numerical model's results against those obtained experimentally. In addition to considering the interior air flow and temperature field in the vehicle, the environment thermal phenomenon and the vehicle's HVAC system were also considered. Experiments were conducted to verify the model's accuracy.A 3-D model of heat transfer and fluid flow was developed to analyse the vehicle. It was demonstrated that higher inlet air velocity can distribute cool air with much more effective by producing more turbulence and faster recirculation vortices within the passenger's compartment. The decrease of high temperature contour near the passenger's feet at front compartment as higher inlet air velocity were due to the air stream were obstructed by front seat to the area. Different velocity and temperature distributions can be obtained by selecting different blower fan speed for without changing HVAC cooling load. Comparing the experimental results with the numerical analysis, the predicted temperature distribution of the air in the vehicle passenger compartment interior was in good agreement with that obtained experimentally.

\section{Acknowledgement}

The authors would like to thank the Universiti Tun Hussein Onn Malaysia and Ministry of Education Malaysia for supporting this research.

\section{References}

[1]. Awbi, H. B. (2003). Ventilation of buildings. Taylor \& Francis

[2]. Boldo, E., Medina, S., Le Tertre, A., Hurley, F., Mücke, H. G., Ballester, F., \& Aguilera, I. (2006). Apheis: Health impact assessment of long-term exposure to PM2.5 in 23 European cities. European journal of epidemiology, 21(6), 449-458

[3]. Finkelstein MM, Jerrett M, Sears MR. Traffic air pollution and mortality rate advancement periods. Am J Epidemiol 2004; 160: 173-177 
[4]. Mechler R, Amann M, Scho“pp W. A methodology to estimate changes in statistical life expectancy due to the control of particulate matter air pollution. Interim Reports. International Institute for Applied Systems Analysis (IIASA), 2002

[5]. H. Mohamed, N. Kamsah, A. Miski, and M. Nor, "Numerical Analysis of Air-Flow and Temperature Field in a Passenger Car Compartment," vol. 862, no. Imat 2011, pp.854-862, 2012

[6]. P. Danca, F. Bode, I. Nastase, and A. Meslem, "CFD simulation of a cabin thermal environment with and without human body - thermal comfort evaluation," vol. 01018, pp. 1-8, 2018

[7]. H. Zhang, L. Dai, G. Xu, Y. Li, W. Chen, and W. Tao, "Studies of air-flow and temperature fields inside a passenger compartment for improving thermal comfort and saving energy. Part I : Test / numerical model and validation Studies of air-flow and temperature fields inside a passenger compartment for improving thermal comfort and saving energy . Part I : Test / numerical model and validation," Appl. Therm. Eng., vol. 29, no. 10, pp. 2022-2027, 2009

[8]. T. Han, K. Chen, A. Curran, J. Pryor, and M. Hepokoski, "Assessment of Various Environmental Thermal Loads on Passenger Thermal Comfort," vol. 3, no. 1, pp. 830-841, 2018

[9]. J. Woon, E. Young, S. Hyuk, H. Sun, S. Choi, and Y. Kim, "International Journal of Thermal Sciences In fl uence of the spectral solar radiation on the air fl ow and temperature distributions in a passenger compartment," vol. 75, pp. 36-44, 2014

[10]. Y. Mei, "3-D Numerical And Experimental Analysis For Airflow Within A Passenger Compartment," Vol. 9, No. 4, Pp. 437-445, 2008

[11]. J. M. Jalil and H. Q. Alwan, “CFD Simulation for a Road Vehicle Cabin,” vol. 18, no.2, pp. 123-142, 2007.

[12]. M. Kiliç and G. Sevilgen, "The effects of using different type of inlet vents on the thermal characteristics of the automobile cabin and the human body during cooling period," vol. c, pp. 799-809, 2012

[13]. M. Kilic and G. Sevilgen, "Numerical Heat Transfer, Part A : Applications : An International Journal of Computation and Methodology Evaluation of Heat Transfer Characteristics in an Automobile Cabin with a Virtual Manikin During Heating Period," no. November 2014, pp. 37-41

[14]. Zainal Abidin, S. F., Zulkefli, M. H., Mohmad Ja'at, N., \& Hassan, M. N. (2021). Effect of Camshaft Degreeing towards Performance of a Passenger Car. Fuel, Mixture Formation and Combustion Process, 3(1)

[15]. Baharol Maji, D. S., \& Mustaffa, N. (2021). CFD Analysis of Rear-Spoilers Effectiveness on Sedan Vehicle in Compliance with Malaysia National Speed Limit. Fuel, Mixture Formation and Combustion Process, 3(1)

[16]. Azlan, A. N., Abd Rashid, R., Ishak, I. A., Mohd Salleh, Z., Madon, R. H., Ishak, M. Z., \& Samiran, N. A. (2021). Three Dimensional CFD Simulation of Air-Blown Gasification in a Downdraft Reactor: Effect of Throat Diameter and Air Inlet Position. Fuel, Mixture Formation and Combustion Process, 3(1)

[17]. G. Campus, "Transient numerical analysis of airflow and heat transfer in a vehicle cabin during heating period Gökhan Sevilgen and Muhsin Kilic *," vol. 52, pp. 144-159, 2010

[18]. J. P. Rugh, L. Chaney, and J. Lustbader, "Reduction in Vehicle Temperatures and Fuel Use from Cabin Ventilation, Solar-Reflective Paint, and a New Solar-Reflective Glazing," no. 724, 2018

[19]. A. Fujita, J. Kanemaru, H. Nakagawa, and Y. Ozeki, "Numerical simulation method to predict the thermal environment inside a car cabin," vol. 22, 2001

[20]. J. H. Moon, J. W. Lee, C. H. Jeong, and S. H. Lee, "International Journal of Thermal Sciences Thermal comfort analysis in a passenger compartment considering the solar radiation effect," Int. J. Therm. Sci., vol. 107, pp. 77-88, 2016 